\title{
Políticas públicas y Cotidianidad RURAL-URBANA. UNA APROXIMACIÓN SOCIO- ANTROPOLÓGICA A LAS CONCEPCIONES DE PLANES Y PROGRAMAS AGROPECUARIOS (Santa Fe- Argentina)
}

Public policies and rural-urban daily life. A socio-anthropological approach to the conceptions of agricultural plans and programs (Santa Fe, Argentina)

\author{
Marina Eliana Espoturno \\ marinaina5@gmail.com \\ IICAR-CONICET- GEA-CEACU
}

RESUMEN: En el siguiente artículo me propongo analizar desde una perspectiva socio-antropológica una de las políticas públicas existentes en Argentina que se desarrolla en experiencias locales en una ciudad del sur de la provincia de Santa Fe: el Programa Cambio Rural II (INTA-Ministerio de Agroindustria). Para ello focalizaré en las experiencias de dos grupos, uno de productores de cerdos y otro de horticultores. El análisis de la letra de esta política pública me posibilitará identificar las concepciones sobre los sujetos, y a partir de los registros de campo generados en entrevistas y observaciones, podré dar cuenta de las experiencias concretas en la localidad. El análisis de Cambio Rural II es relevante también porque se enmarca en el Plan Estratégico Agroindustrial y Agroalimentario 2010-2020 (PEA), que hoy día marca los lineamientos generales del sector agropecuario a nivel nacional, y a su vez articula con un programa local de producción y comercialización de alimentos denominado Municipio Sustentable.

Palabras clave: Políticas públicas; Cotidianidad; Sector agropecuario; Argentina. 


\section{ABSTRACT:}

In the following article I take a socio-anthropological perspective to analyze one of the public policies in Argentina that is being developed in a city of the south of Santa Fe province: the Cambio Rural II program (INTA- Ministry of Agri-industry). To this end, I focus on the experiences of two groups: a group of pig farmers and a group of horticulturists. Through an analysis of the wording of this public policy, I identify the conceptions about the subjects, and I draw on the field records from my interviews and observations to describe specific experiences in the town. The analysis of Cambio Rural II is also relevant because it is part of the Plan Estratégico Agroindustrial y Agroalimentario 2010-2020 (Agri-industry and Agri-food Strategic Plan, PEA), which today sets the general guidelines of the agricultural sector at the national level, and also combines with the Municipio Sustentable local food production and commercialization program.

KEYWORDS: daily life; agricultural sector; Argentina.

\section{Introducción}

$\mathrm{E}$ siguiente artículo se desprende de una investigación doctoral en curso en la que me propongo abordar las prácticas y los sentidos que construyen habitantes y productores agropecuarios de una localidad del sur de la provincia de Santa Fe (Argentina) en relación al ambiente en un contexto de conflictividad por el uso de agrotóxicos. Este contexto de conflictividad, de abierto cuestionamiento al modelo del agronegocio en muchas localidades de la pampa húmeda, zona núcleo de la producción agropecuaria en Argentina, se vincula a las características centrales del mismo: la tendencia al monocultivo, la gran dependencia de insumos, la concentración de tierras y de la producción, la exclusión de una variedad de productores, la convivencia entre las actividades productivas y la población en esos límites, a veces difusos y disputados de lo rural y lo urbano. 
En el marco contextual brevemente explicitado previamente, y a partir del trabajo de campo en marcha desde el año 2015, se fue haciendo insoslayable para la comprensión de la problemática a investigar abordar el lugar de las políticas públicas, las vinculaciones entre diferentes programas estatales y cómo estos son pensados y apropiados por diferentes sujetos en el territorio. Por ello, en este artículo me propongo analizar una de las políticas públicas existentes a nivel nacional y que toma carnadura en experiencias locales: el Programa Cambio Rural II (INTA ${ }^{1}$-Ministerio de Agroindustria). El análisis de Cambio Rural II es relevante también porque se enmarca en el Plan Estratégico Agroindustrial y Agroalimentario 2010-2020 (PEA), que hoy día marca los lineamientos generales del sector agropecuario a nivel nacional, y a su vez articula con un programa local de producción y comercialización de alimentos denominado Municipio Sustentable. El análisis de la letra de esta política pública me posibilitará identificar las concepciones sobre los sujetos, y a partir de los registros de campo generados en entrevistas y observaciones, podré dar cuenta de las experiencias concretas en la localidad. Para el análisis, focalizaré en las experiencias de dos grupos, uno de productores de cerdos y otro de horticultores. La elección de estos dos grupos se debe a que de los cuatro existentes en la localidad (cerdos, horticultura, ganadería y caprinos) la mayoría de los establecimientos dedicados a las actividades de cría de cerdos y de horticultura se hallan en el periurbano de la localidad. Además son grupos constituidos por pequeños y medianos productores familiares, que a su vez tienen heterogeneidades al interior de cada uno de los grupos. Finalmente, los grupos de cerdos y horticultura han sido los más accesibles y sobre los que se pudo hacer un seguimiento más constante.

Partiendo de la concepción de que la etnografía es «el proceso de documentar lo no documentado» (Rockwell, 2011, p.48), consideramos que indagar sobre las prácticas y sentidos de los sujetos es una forma de llevar a cabo nuestra labor etnográfica, y de otorgarle especificidad a una problemática que podría ser abordada desde una diversidad de perspectivas y disciplinas científicas. La investigación es guiada desde un enfoque antropológico relacional que recupera la cotidianidad (Heller, 1977) y las construcciones de

1. Instituto Nacional de Tecnología Agropecuaria. 
sentido de los sujetos. Esta perspectiva permite observar y relacionar tanto las tendencias generales que atraviesan a las experiencias particulares como su carácter de historicidad (Achilli, 2005).

Para abordar la cotidianidad de los sujetos en sus experiencias concretas con una política pública agraria es necesario caracterizar la localidad en donde llevo a cabo el trabajo, reconocer las particularidades de esos territorios donde lo urbano y lo rural tiene intimas conexiones, superposiciones y tensiones; como plantea Giarraca (2003) «se trata de pensar espacios analíticos en donde se destaquen más las imbricaciones, las superposiciones, en lugar de aquellos aspectos que habilitan a pensarlo como mundos sociales separados» (p.18). La localidad está ubicada en el sur de la provincia de Santa Fe (Argentina), zona núcleo de la producción agrícola y del agro-negocio pampeano; según datos de la Secretaría de Agroindustria de la Nación en el departamento al que pertenece la localidad, durante la campaña 2017/2018 se sembraron 540.350 ha de soja (cultivo predominante de la región). Desde su cartografía hasta su envergadura como ciudad la erigen como enclave relevante del modelo sojero, ciudad-gestión (Cloquell et al, 2014) que concentra buena parte de las empresas transnacionales que hacen a la producción, comercialización y transformación de commodities. Cuenta con instituciones técnicas agropecuarias, educativas agrotécnicas, empresas de insumos para el agro (destacando los semilleros) y una importante cantidad de industrias que incluyen: siderurgia, metal mecánica, textil y construcción; también fue creciendo como centro de servicios y administrativo, incluso para los habitantes de pequeñas localidades cercanas. A su vez la cercanía al puerto de Rosario es estratégico para la exportación de la producción.

Dadas algunas características estructurales de la localidad, el sector agropecuario ocupa un lugar relevante, ya sea por la dimensión de la producción agrícola y los ingresos que genera, como por la forma en que atraviesa la dinámica social ya que persiste en gran parte de la población la idea de que «se vive del campo»; e incluso el valor de la tierra en la zona impacta en los precios de los alquileres de viviendas y en los precios de los terrenos. Sin embargo, también se destaca al sector industrial, en la localidad bastante relacionado con el agropecuario, como un importante generador de empleo 
«La trama productiva, el entramado productivo responde a una localidad con una gran influencia del sector agropecuario, no integrado...lo principal no necesariamente es el sector primario de la producción, hay también una trama industrial muy importante, un desarrollo industrial muy importante. Hay un parque industrial, que muchas de las empresas están ligadas al sector agropecuario, podemos hablar de una agroindustria. $\mathrm{Y}$ tenemos un, el sector terciario de la economía, la de servicios también muy desarrollado, muchos vinculados también al sector agropecuario, y otros ligados a los servicios en general» (Funcionario municipal, 06/2016).

Como plantean Cloquell y otras (2014) los pueblos rurales (en nuestro caso ciudad) permiten observar los procesos de transformación y son expresión de una ruralidad cambiante, así como de una forma de vida urbana atravesada por la industrialización de la agricultura y la gestión de la misma en su seno. En la región pampeana de Argentina, un punto nodal de esa relación de lo rural y urbano lo constituyen los periurbanos de los pueblos y ciudades. Entendemos a los mismos como un área de transición en permanente transformación y con un abanico heterogéneo para los usos del suelo (Barsky, 2005; Perez et al, 2013), que vincula los espacios productivos, de comercialización y consumo con la población de las localidades urbano-rurales y su cotidianidad. Barsky sostiene que los periurbanos constituyen «un territorio de borde sometido a procesos económicos relacionados con la valorización capitalista del espacio» (Barsky; 2005: 4), y ampliando esa idea, retomamos a Cloquell y otras (2014) que expresan que las condiciones estructurales de los pueblos rurales de la región pampeana dan lugar al importante posicionamiento del capital global.

A partir de lo anterior podemos pensar que la ocupación de los periurbanos en la región pampeana puede ser un proceso no planificado, con un crecimiento marcadamente acelerado dada la importancia de la producción agraria en la economía nacional.

No había una división bien marcada de 'acá comienza el periurbano y acá comienza el urbano', incluso, las planchitas de catastral o los diseños de ciudad no tenían la zona de descanso o de relax que es la zona suburbana; nosotros teníamos lo urbano y lo rural [...] El periurbano no tenía un límite sino que era 'acá se pone la casa, acá se siembra', era así primeramente; y así son la mayoría de los pueblos de la Pampa Húmeda (Trabajador municipal, 04/2018). 
Es interesante cómo a partir del extracto de entrevista anterior se vislumbra la dificultad de definir ese periurbano, sobre todo si consideramos que en esa delimitación aparecen en consideración procesos sociales, políticos, económicos, productivos e históricos que lo constituyen junto con aspectos de orden más burocrático y técnico como un trámite catastral, lo cual es central para la «gestión» de las ciudades.

Ese «lugar de borde» que constituye el periurbano local, se hace evidente como un espacio a partir del conflicto; identificado este último como disputas por el desarrollo urbanístico y la producción agropecuaria principalmente, pero que refieren de un modo más amplio a los usos del suelo, las prácticas productivas, los patrones de asentamientos de la población. En este marco de hegemonía capitalista en la producción agropecuaria la producción de commodities es una forma de captación de ganancias extraordinarias, entre otras cosas, por una serie de políticas públicas que delinean los rumbos generales del sector agropecuario. Sin embargo, las políticas públicas también son heterogéneas y constituyen campos a través de las cuales se expresan contradicciones, tensiones, sentidos y apropiaciones.

Teniendo en cuenta el objetivo de este artículo, en un primer apartado será definido qué entiendo por políticas públicas y la particularidad de un abordaje de estas desde una perspectiva antropológica; a continuación haré un breve análisis de la letra del programa Municipio Sustentable, de Cambio Rural II y el PEA 2010-2020 en dónde se considerarán sus objetivos, y la construcción de sujeto agrario que realizan. En un segundo apartado se analizará cómo el programa Cambio Rural II se inscribe en la cotidianidad de algunos sujetos que forman parte de experiencias concretas de dicha política pública. Por último, se plantearán algunas consideraciones finales que nos permitan elaborar algunas síntesis.

\section{De planes y programas agropecuarios. Una mirada antropológica}

Para dar inicio a esta reflexión sobre las políticas públicas es necesario, como primer paso, explicitar qué entiendo por «políticas públicas». Autoras como Achilli (1998) y Shore (2009) ya han planteado esta necesidad. En tal 
sentido, Shore plantea que «la manera en que las definimos o cómo nos aproximamos a las políticas depende de lo que entendemos por políticas» (Shore, 2009 , p. 6). Aún más, a la autora le interesa cómo abordar antropológicamente el análisis de las políticas y los aportes que se pueden realizar desde esta disciplina.

El enfoque antropológico de las políticas públicas que recupero lleva la marca de una particular forma de entender y hacer antropología que pondera el lugar de los sujetos y sus construcciones de sentido, vinculándolos a condiciones materiales e históricas de existencia, producción y de prácticas sociales. Además supone un prolongado y profundo trabajo de campo que posibilita «documentar lo no documentado» (Rockwell, 2011, p. 48). De ahí que la recuperación de la cotidianidad social de los sujetos es una de las características que considero centrales de la perspectiva antropológica elegida. Es la documentación del cotidiano lo que nos permite hacer especiales aportes a la forma en que los sujetos viven y conciben a las políticas públicas. A su vez, retomo a Achilli (1998) quien considera a las políticas públicas en tanto incluyen los procesos y actuaciones desplegados tanto por organizaciones e instituciones estatales (para nuestro caso, el gobierno municipal y nacional, INTA) como por los diferentes sujetos implicados (productores agropecuarios, ingenieros agrónomos, veterinarios). Las políticas públicas son entendidas como espacios de conflicto, de lucha por intereses diferenciados que, en su desenvolvimiento, pueden ser reforzadas, rechazadas, confrontadas (Achilli, 1998).

Con esto quiero decir que me alejo de aquellas concepciones que entienden que las políticas públicas y su análisis es una mera cuestión superestructural, que atañe exclusivamente a las dinámicas y características del aparato del Estado, como monolítico y libre de contradicciones, o aquellas que ven en las políticas un asunto de expertos, tecnicismos y cuanto mucho sólo queda evaluar el impacto o sus efectos sobre la población objeto. Pensar a las políticas públicas desde una perspectiva que supera lo gubernamental e incluye a las prácticas y sentidos de los sujetos puede colaborar a una reflexión y análisis del Estado, en su sentido ampliado, así como de los procesos de construcción de hegemonía y de las conflictividades que pueden generarse. 
A continuación abordaré algunas cuestiones centrales del PEA ya que constituye un plan nacional marco para las políticas públicas agrarias existentes. Los lineamientos allí expresados nos permitirán comprender el contexto en que se da el programa Cambio Rural II, así como los objetivos propuestos en este último. También repasaré los aspectos centrales del programa Municipio Sustentable, ya que como política pública local articula con Cambio Rural II.

En el año 2010, se lanza a nivel nacional el Plan Estratégico Agroalimentario y Agroindustrial Participativo y Federal 2010-2020 (PEA). Como señalan Carballo González y otros (2012) este plan nacional surge luego de más de 30 años de inexistencia de una planificación por parte del Estado, ya que los planes antecedentes fueron en los años 1974 y 1984. Sin embargo, pensamos que esos más de 30 años en que el Estado se retiró para dar paso a «las leyes del mercado» hay que leerlas en clave de otra forma de definición sobre el rumbo de la producción agropecuaria, y por ello retomamos a Borón (2001) cuando plantea que «lo que se denomina «desregulación» no es otra cosa que la imposición de una nueva modalidad de regulación (...). No se trata, en consecuencia, de regulación sí o no, sino de quién fija las normas regulatorias y con vistas a cuáles intereses» (p. 10).

Considero que la existencia del PEA hay que pensarla tanto en el rol histórico de Argentina en la producción agropecuaria, así como en el contexto que se abre en Argentina luego del 2001, con la devaluación de la moneda, y en las tendencias regionales y mundiales sobre la producción agrícola. Incluso, no podemos dejar de relacionarlo con otras políticas que funcionan a otras escalas, como Cambio Rural II y Municipio Sustentable. Esto nos puede permitir buscar los nexos entre diferentes escalas, y las formas en que se manifiestan continuidades y contradicciones entre ellas, tanto en la letra como en la experiencia de los sujetos ${ }^{2}$.

Tal como su nombre lo dice, el Plan Estratégico Agroalimentario y Agroindustrial 2010-2020 (PEA), se propone como un marco general a partir del cual definir y poner en práctica diversas políticas públicas que permitan

2. La noción de escala la retomo de Achilli (2014), por lo cual un análisis que contemple las diferentes escalas de las políticas públicas supone un particular abordaje teórico-metodológico, e incluso un desafío analítico y de escritura que ha instancias de este trabajo intentaré iniciar. 
alcanzar los objetivos y metas allí propuestas. El PEA plantea una «visión» que sintetiza los aportes de todos los participantes involucrados en la elaboración del plan ${ }^{3}$; a partir de esta visión se proponen responder a la pregunta: «¿Qué queremos que el Sector Agroalimentario y Agroindustrial sea en el futuro?»

Argentina será líder mundial en la producción de bienes y servicios agroalimentarios y agroindustriales, de calidad y con valor agregado, en particular en origen, asegurando al mismo tiempo la provisión alimentaria nacional y satisfaciendo la demanda internacional en cantidad y calidad, en un marco de equidad territorial, inclusión social y sustentabilidad ambiental, económica y social, promoviendo de esa forma el desarrollo de la Nación y sus regiones. (PEA, p. 84)

El Plan expresa objetivos que se hallan relacionados a cuatro fines principales, los mismos se dividen en: «Fin Estratégico Económico-Productivo», «Fin Estratégico Socio-Cultural», «Fin Estratégico Institucional» $\mathrm{y}$ «Fin Estratégico Ambiental-Territorial». A pesar de contar con estos fines, que a primera vista sugieren un abordaje de la realidad agropecuaria considerando su complejidad, de la lectura del PEA se desprende una priorización del Fin Estratégico Económico-Productivo por sobre los demás. Entre las principales metas para el período se estableció el incremento de la producción de granos, que para 2020 se propone el objetivo de alcanzar las 157 toneladas $^{4}$, lo cual representa un 58\% más con respecto al año 2010(PEA, p. 96) e implicaría la necesidad de ampliar la superficie dedicada a agricultura aproximadamente un 27\% (Taddei, 2013), también con referencia a 2010. Estos números son importantes para contextualizar los análisis sobre la conflictividad ambiental y territorial en Argentina, así como para dar cuenta sobre los diversos sujetos agrarios, su lugar en la producción y en las políticas públicas impulsadas.

3. Participaron en la elaboración del PEA: Autoridades nacionales de diferentes Ministerios, Ministerio de Agricultura, Ganadería y Pesca y representantes de sus respectivas Secretarías y Sub-secretarias, organismos descentralizados, 22 gobiernos provinciales y unidades académicas públicas y privadas.

4. En una nota de Infobae del 26/09/2017 se informa que la campaña 2016/2017 cerró con 136,6 millones de th de granos producidos, lo cual representa un 9,3\% de aumento en relación al ciclo anterior. Incluso se resalta que según la consultora que realizó el trabajo, la cosecha record fue posible gracias a la recuperación de la producción de cereales y el mayor uso de tecnología. https:/www.infobae.com/economia/2017/09/26/ cosecha-record-para-la-argentina-136-millones-de-toneladas/ 
Otro aspecto que quisiera retomar del PEA es la caracterización del sujeto agrario que realiza, Shore (2009) afirma que las políticas públicas inciden en la construcción de la subjetividad y en nuevas identidades o sujetos políticos. En el Plan se afirma que en el siglo XX el sujeto agrario «era el productor rural que concentraba en sí la propiedad de la tierra y las maquinarias, poseía el capital necesario para enfrentar las campañas de siembra (o bien asumía la deuda) y era el responsable de la gestión agrícola y empresarial de su producción» (PEA, p. 43). Considero que esta definición no sólo es imprecisa sino también homogeneizante ${ }^{5}$ al ocultar la diversidad de sujetos agrarios que habitan y habitaron el país y las variadas formas de llevar a cabo la producción; incluso quedan desdibujadas las condiciones sociales y económicas de vida, producción y reproducción. Según el PEA, en el siglo XXI existe un nuevo sujeto agrario: el «emprendedor agropecuario», que no necesariamente es el propietario de la tierra y se caracteriza por «una actitud claramente positiva hacia la incorporación de tecnología, una neta vocación por la productividad, capacidad de asumir el riesgo, incorporación de conocimiento para la gestión e innovación y motivación emprendedora» (PEA: 44). La noción de «emprendedor», es una categoría que tiene profundas conexiones con el neoliberalismo como forma histórica del capitalismo y como ideología (Galbraith, 1992), fuertemente impulsada desde organismos internacionales como el Banco Mundial y el BID, y recuperada desde las políticas públicas. Si consideramos el desarrollo y avance del capitalismo en el agro argentino, no es de extrañar que desde hace unos años la figura del emprendedor también sea el horizonte en la producción agropecuaria. Interesa resaltar que con esta denominación predomina una visión empresarial de la actividad, donde las acciones del «individuo» son resultado de una racionalidad económica y utilitarista exclusivamente. Si decimos que desde las políticas públicas también se construyen subjetividades, al generalizar al emprendedor agropecuario como el sujeto social actual se impulsan valores vinculados al individualismos y al sujeto como «empresario del yo» (Delgado, 2018). También se invisibiliza

5. Desde inicios del siglo XX (e incluso antes) el agro en Argentina contó con diversos sujetos vinculados a la producción agropecuaria. En la zona núcleo maicera los arrendatarios fueron sujetos relevantes, no sólo en número sino también por procesos histórico-sociales que protagonizaron (Grito de Alcorta). Y si se amplía aún más la visión, los productores campesinos habitan a lo largo y ancho del país produciendo para las economías locales. 
la variedad de sujetos agrarios a nivel nacional, y a su vez busca contraponer a los dos tipos de productores descriptos (el del siglo XX y el del siglo XXI) apelando a la clásica contraposición «moderno-atrasado». Claramente, ese «emprendedor agropecuario» será el sujeto destinatario de este Plan y de muchas otras políticas públicas.

Relacionado a la definición del sujeto agrario está el modelo de desarrollo que propone el PEA. Retomamos nuevamente a Shore (2009) cuando dice: «las políticas reflejan maneras de pensar sobre el mundo y cómo actuar en él. Contienen modelos implícitos - y algunas veces explícitos- de una sociedad y de visiones de cómo los individuos deben relacionarse con la sociedad y los unos con los otros» (p. 11). El Plan define dos modelos, uno que sería el histórico del país y otro al que se apunta con este plan. El primero es el «Modelo Incremental», está basado en la producción primaria de commodities y su exportación. El segundo es el «Modelo de Valor Agregado con Desarrollo», este se propone profundizar una tendencia de los últimos años: la generación de valor agregado en origen y la inserción de Argentina en las cadenas globales de valor. Desde el PEA se aclara que estos dos modelos no son excluyentes entre sí, ya que ambos le permiten al país un crecimiento; sin embargo, el segundo «nos permite aprovechar al máximo las oportunidades que el mundo nos presenta y ofrece» (PEA, p. 80). Es evidente que el Plan no viene a romper la matriz productiva histórica, solo la aggiorna a los tiempos y las demandas que corren. La propuesta complementaria de generación de valor agregado al centrarse en fines económicos-productivos abona a la profundización de relaciones capitalista en el campo, lo cual genera situaciones de vulnerabilidad entre algunos sujetos agrarios al amenazar su continuidad en la producción y de ciertas formas alternativas de producir y vivir. La priorización del crecimiento del producto por medio del agregado de valor y de las exportaciones son estrategias más cercanas a los sectores más concentrados de la economía agropecuaria nacional: complejos agroindustriales y empresarios agrícolas. Entre los pequeños productores familiares capitalizados de la región pampeana y el campesinado, el agregado de valor aparece más como una estrategia familiar para la reproducción y la producción que como capitalización en el sentido más empresarial. Incluso, estos dos modelos pro- 
puestos y su combinación pueden ser caracterizados como extractivistas ${ }^{6} \mathrm{ya}$ que se asientan en un patrón de acumulación basado en la sobreexplotación de bienes naturales, donde la tasa de extracción se vuelve más alta que la de renovación (Acosta, 2011), y que favorece al proceso de expansión de la frontera de explotación, en este caso agropecuaria (Svampa y Viale, 2017).

El PEA constituye un Plan marco general, a partir del cual elaborar programas y proyectos para ser llevados a cabo. El Programa Cambio Rural II puede entenderse como otra escala dentro de las políticas públicas, el cual se desprende y responde a los lineamientos generales planteados en el PEA.

Cambio Rural es un programa nacional que hunde sus raíces en la década del '90. Hacia el año 1993 fue creado y ejecutado por INTA en todo el territorio nacional; según la propia evaluación que hicieran el Ministerio de Agricultura, Ganadería y Pesca de la Nación (MAGyP) y el INTA «Cambio Rural posibilitó que numerosos productores mejoraran sus indicadores productivos y su capacidad de gestión mediante el acceso al asesoramiento profesional, y lograran escala y competitividad a partir del fomento de la asociatividad» (Programa Cambio Rural II, 2013, p. 2). El programa fue planteado como una política para los sectores menos concentrados del sector agropecuario, sin embargo al plantear como objetivos el mejoramiento de los indicadores productivos y de gestión, y el aumento de escala y competitividad, se fortaleció tanto al sujeto agrario como al modelo de sociedad (Shore, 2009) que se intentó construir a partir de la década del '90. Al respecto, Felipe Solá, Secretario de Agricultura, Ganadería y Pesca de la Nación durante el menemismo, expresaba que lo que hacía falta para acabar con los problemas del agro era «una reforma cultural» ${ }^{7}$, si los productores (sobre todo los pequeños

6. Existen ciertos reparos en considerar a la actividad agrícola (incluso la de monocultivo de soja transgénica) como una actividad extractiva (ver Reboratti 2017). Por ello recupero a Seoane (2013), quien examina los efectos de la generalización de su uso, y destaca la necesidad de una mirada sobre el extractivismo que profundice en la relación con el sistema económico capitalista en su fase neoliberal; considerando la forma de acumulación, las características del orden internacional y la división internacional del trabajo, las características de la nueva revolución científica y la reflexión sobre las características y consecuencias de la crisis que afrontamos. Dichas consideraciones exceden los objetivos de este artículo, pero forman parte de la reflexión del proceso de investigación en el que se inscribe.

7. Felipe Solá «Una reforma cultural»- Clarín Rural, sábado 12 de agosto de 1995, p.5 
y medianos) deseaban sostenerse en la producción necesariamente deberían «innovar», «aumentar la escala», «crecer».

En el año 2013 a instancias del MAGyP y el INTA se lanzó Cambio Rural II. El programa se proponía «contribuir al desarrollo local mediante el aumento y mejora de la producción agropecuaria, pesquera y forestal, el fortalecimiento organizacional de los productores y la facilitación de procesos de agregado de valor» (Programa Cambio Rural II, 2013,p. 4). Podemos ver cierta consonancia con el PEA en relación al objetivo de agregado de valor, y también en las «metas» propuesta, las cuales apuntaron a la incorporación de cada vez mas productores al Programa, el aumento de la productividad global de los emprendimientos y mejoramiento de la actividad productiva primaria, así como con «metas» que se proponían abordar cuestiones vinculadas a la problemática ambiental a partir del impulso de las Buenas Prácticas Agrícolas en el uso de agroquímicos y rotación de cultivos (Programa Cambio Rural II, 2013).

Según sus bases este programa estaba destinado a productores de la agricultura familiar capitalizados o con posibilidades de capitalización y PyMES del sector agropecuario y agroindustrial ${ }^{8}$. Pese a esta cierta distinción de sujetos agrarios, a lo largo de la letra del programa hay una constante definición de estos en términos de «emprendedor», tal como hemos visto que el PEA caracteriza al sujeto de la producción de la actualidad. De este modo, refuerza por medio de una política concreta un perfil de sujeto agrario individual, empresarial.

Quisiera destacar que pese a esta tendencia a la individuación del programa, propone también el trabajo en grupos. Dichos grupos los conforman entre 8 y 12 productores que se juntan por actividad productiva, y similares condiciones y necesidades; cuentan con el asesoramiento técnico de un/a profesional y deben «elaborar un plan de mejoras de sus emprendimientos individuales y grupales» (INTA Informa, 2014, p. 3), contando con el finan-

8. En el año 2017 el Ministerio de Agroindustria modifica las bases del programa, quitando de los destinatarios a la agricultura familiar y a aquellos productores que no hayan nacido en Argentina. Por esta situación más de 800 grupos de productores que estaban en funcionamiento fueron dados de baja. En los nuevos lineamientos se apunta a productores medianos o grandes. Para este artículo me basaré en el programa previo a la modificación ya que el trabajo de campo fue realizado con anterioridad a esta modificación. 
ciamiento del Estado. Como veremos en el próximo apartado, la tensión entre las tendencias individualizantes y las propuestas de trabajo colectivo o asociativo recorren la experiencia de los grupos analizados.

En una nota de INTA Informa del año 2014 se expresaba respecto a Cambio Rural II: «La propuesta es llegar a 2.000 grupos: $60 \%$ de productores familiares capitalizados, $30 \%$ con posibilidad de capitalizarse y $10 \%$ dedicados a actividades nuevas y de valor agregado» (INTA Informa, 2014, p. 2). Incluso comentan respecto a una experiencia en marcha desde los años '90: «Cuando comenzaron en este camino, dedicaban el $70 \%$ de la superficie que trabajaban a la ganadería y el $30 \%$ a la agricultura. Hoy es prácticamente al revés, pero el número de vientres se mantuvo y lo que se hizo fue intensificar la ganadería»(INTA Informa, 2014, p. 2), este fragmento es ilustrativo de cómo a partir de una política pública que inicialmente fue diseñada para «amortiguar las consecuencias de las políticas neoliberales de los noventa» (Ex Ministro de Agricultura, ganadería y Pesca de la Nación Carlos Casamiquela en INTA Informa, 2014, p. 1) se fue llevando a un proceso de agriculturización y concentración iniciado en aquella década y continuado en las siguientes; y a su vez evidencia la conexión con el PEA respecto a la priorización de metas productivistas que se alejan de aquellas vinculadas a aspectos ambientales.

Finalmente, voy a referir algunas características centrales del programa Municipio Sustentable. Dicha política pública surge en el año 2014, y constituye la primera experiencia a nivel nacional de este programa, impulsado por el entonces Ministerio de Agricultura, Ganadería y Pesca de la Nación y contando con el apoyo del INTA. Es interesante resaltar que en parte su iniciativa estuvo vinculada a constituir formas de intervención en los espacios del periurbano, donde a causa de reclamos por parte de la población respecto a las fumigaciones, se buscaba generar cambios en las formas de producir. También el Estado local partía del diagnóstico que pese a contar con tierras fértiles, un periurbano productivo con potencialidad para la producción de alimentos de consumo local (hortalizas, leche, carnes), productores y mano de obra disponible, instituciones técnicas agropecuarias y un amplio número de potenciales consumidores, la mayor parte de los alimentos básicos consumidos en la localidad provenían de mercados de concentración lejanos y a costos mayores dados los gastos de flete para el transporte. En ese sentido, 
el programa se propuso como meta «organizar localmente la producción de los alimentos que se consumen, así como también su elaboración y comercialización, a través de proyectos productivos con eje en el asociativismo y en el rol activo del estado»(programa «Municipio Sustentable», 2014). Esta política pública local, desde el inicio, buscó articular con Cambio Rural II; de ese modo los grupos de Cambio Rural II constituidos se sumaron a este programa y algunas de las producciones participaron de instancias de comercialización local. Considero interesante llamar la atención respecto que el proceso de agriculturización y concentración que luego devino en monocultivo de soja se asocia a situaciones de conflictividad de varias localidades agrarias de la región pampeana (como la que es foco del trabajo), donde pese a contar con las condiciones materiales para la producción de alimentos, se producen commodities alejados de las necesidades de consumo de la población local.

\section{Las políticas públicas en las experiencias cotidianas}

Hasta el momento he subrayado algunas cuestiones centrales que surgen de la lectura de los proyectos de políticas públicas, ahora intentaré dar cuenta de cómo estas políticas son vividas por los sujetos poniendo en tensión la letra y la experiencia. Como he adelantado, la perspectiva teórica-metodológica desde la cual abordo la investigación le otorga especial centralidad a las construcciones de sentido de los sujetos y en ellas incluidas sus prácticas. Para ello recupero la categoría de cotidianidad como la plantea Agnes Heller (1977), la cual incluye todo tipo de actividades que garantizan la reproducción individual y social, así como la apropiación cultural (Rockwell, 1994). La perspectiva de Heller (1977) destaca que esas actividades son heterogéneas, ya sea por el tipo de sociedad donde se vive, el lugar que se ocupa en la división social del trabajo, la fase de la vida que atraviesa el sujeto; de este modo se incorpora la perspectiva histórica en la vida cotidiana, «en tal sentido, posibilita considerar la conformación de modificaciones que se producen en la cotidianeidad tanto a modo de reproducciones o conservaciones como, también, a modo de 'fermentos secretos de la historia' que anticipa ciertos cambios») (Achilli, 2005, p. 21). Recuperar las experiencias cotidianas de los sujetos para el análisis de las políticas públicas nos permitirá entender de la forma en que los 
sujetos las experimentan, crean, re-crean, discuten, rechazan o adaptan a sus intereses y necesidades.

En relación a las experiencias concretas del Programa Cambio Rural II, he tenido la oportunidad de acercarme a dos experiencias de grupos en la localidad donde llevo a cabo el trabajo de investigación: uno de productores de cerdos y otro de horticultores ${ }^{9}$. Los dos grupos se conforman en el año 2015 y han tenido trayectorias diversas. Los grupos de Cambio Rural II tienen que estar conformados por un mínimo de 8 productores y un máximo de 12 , un asesor que es un profesional elegido por el grupo que brinda apoyo técnico y un agente de proyecto perteneciente a INTA que acompaña al grupo y apoya el trabajo del asesor. La particularidad de este programa en la localidad es que en varias acciones coordina con otra política pública impulsada desde el Estado local: el programa Municipio Sustentable. Es posible observar una articulación entre dos políticas públicas, una de orden nacional y otra local, a partir de algunos objetivos en común, el compartir un territorio y de apuntar a similares sujetos de la producción. En el año 2015 a instancias del programa local, y con los grupos de cambio rural funcionando, se realizo una encuesta de consumo de alimentos en 4 barrios periféricos de la localidad con el fin de planificar en conjunto algunas líneas de acción que potenciaran la producción de alimentos en el periurbano y el consumo local. Interesa destacar que en el programa Municipio Sustentable además de los productores familiares del periurbano, eran centrales los habitantes de los barrios periféricos y más pobres de la localidad. La articulación de estas dos políticas públicas suponía un desafío ya que constituía una instancia donde la vinculación de lo urbano y lo rural se evidenciaba.

El grupo de productores de cerdos está conformado por 8 productores de la localidad, un asesor veterinario y una ingeniera agrónoma de INTA agente de proyecto. Existe una gran heterogeneidad entre los productores: la productora más grande tiene aproximadamente 60 animales y el más chico 5 , algunos producen y venden animales para faenar a frigoríficos y otros venden lechones a particulares, hay productores con cierta tradición en la actividad

9. Vinculada a la modificación en los destinatarios de la política pública, para el año 2018 ninguno de los dos grupos continua funcionando. 
y otros que recién inician (y entre estos también hay diferencia de capital económico).

El grupo ha llevado a cabo algunas experiencias de faena y comercialización directa en la localidad, las cuales han dejado al descubierto diferencias entre los productores no sólo por cuestiones materiales entre ellos (como cantidad de animales, tamaño de los animales, disponibilidad de insumos) sino también por los objetivos individuales, muchos de los cuales no coinciden con los del programa Cambio Rural II y del asesor, estos últimos están enfocados en alcanzar determinados estándares de producción, que en algunos casos se asocian a la incorporación de tecnología y la especialización en un tipo de producto (capón ${ }^{10}$ ).

En 2016 se realizó en la oficina local de INTA un taller con los productores porcinos con el fin de evaluar la primera experiencia de comercialización directa; de este taller participaron los productores, el asesor veterinario, la agente de INTA, miembros de IPAF ${ }^{11}$-INTA, representantes de la municipalidad y representantes de la Facultad de Ciencias Agrarias de la Universidad Nacional de Rosario. Antes de iniciar el taller la agente de proyecto de INTA proyectó una parte de un video institucional sobre Cambio Rural en donde se hablaba de la producción porcina en relación al asociativismo como estrategia para exportar la producción, y se expresaba que en Argentina quienes están llevando adelante esa estrategia y cubriendo esa demanda son los grandes productores (aproximadamente 10.000 animales faenados semanales) porque «son los que tienen más conciencia de la importancia del asociativismo. [...] los más chicos son los más individualistas» (Registro de campo: Taller de productores porcinos, 2016). Es interesante ver cómo desde el INTA se transmiten y refuerzan este tipo de concepciones que dejan de lado todo análisis de tipo histórico y estructural y concluyen que las posibilidades o dificultades son resultado de decisiones personales o características constitutivas de cierto tipo de productor. Incluso en una intervención en una reunión el

10. El capón es el cerdo macho castrado destinado a faena, se lo considera en esa categoría a partir de los $90 \mathrm{~kg}$.

11. Instituto de Investigación y Desarrollo Tecnológico para la Pequeña Agricultura Familiar. 
asesor del grupo planteó que «en el grupo hay productores más pro-activos y otros que necesitan ser empujados», y que «es necesario que todos en el grupo empiecen a producir capones y dejar de ser lechoneros si nos vamos a empezar a dedicar a la comercialización» (Registro de campo, 06/10/2016). Este tipo de afirmaciones han sido hechas también por aquellos productores más grandes del grupo, quienes generalmente fueron los que aportaron animales para la comercialización colectiva; mientras que los que se dedican a la producción de lechones han reafirmaron su identidad «lechonera» en varias ocasiones diciendo que «yo recién estoy empezando en la producción»o «a mí me sirve, es lo que sé hacer» (Registro de campo: Taller de productores porcinos, 2016).

Las diferencias internas entre los productores por el tipo de animal producido (lechón o capón) generaban roces entre los miembros del grupo, sobre todo a la hora de encarar proyectos del orden de lo colectivo como la comercialización. Por ejemplo, en la segunda experiencia de comercialización grupal y directa uno de los productores que se había comprometido a aportar los animales no lo hizo porque ya los había vendido al surgirle una oportunidad; eso trajo mucho malestar porque los mismos productores que habían aportado animales en la primera experiencia tuvieron que volver a hacerlo. Luego de esta situación y como estimulo a la producción de capones, entre los productores, el asesor y la agente de INTA acordaron que en la próxima faena se le pagaría un $20 \%$ más que el precio de pizarra a quien aportara ese tipo de animal.

Un actor importante para el sostenimiento de este grupo era la municipalidad, ya que a partir del programa local Municipio Sustentable se facilitaban habilitaciones para comercializar, se prestaba ayuda económica para el alquiler de la sala de faena y colaboraban con las actividades de difusión en las instancias de comercialización. Uno de los productores en una reunión manifestó que de no ser por la ayuda de la municipalidad deberían aumentar el precio de venta de la carne y ya no sería un producto atractivo. Al respecto de este comentario, el representante de la municipalidad que seguía más de cerca al grupo expresó que había notado que muy poca gente de los sectores más pobres de la localidad se había acercado a comprar, 
Al municipio le interesa que esa gente pueda... es una prioridad para el municipio, porque por eso se hizo el revelamiento de consumo en algunos barrios periféricos. [...] el municipio puede financiar pero no a individuos, sino como parte de una política que incluya a los pobladores de la localidad. (Registro de campo, 22/06/2016).

Es interesante cómo a partir de la articulación entre dos políticas públicas, se definen intereses, alianzas y también se generan estrategias por parte de los diferentes sujetos involucrados. A partir del planteo de la municipalidad, una de las productoras propuso en la reunión que a partir de las vecinales se ofrezcan los bolsones con cortes de carne de cerdo a los pobladores de los barrios de la localidad, y por otro lado poder ofrecer diferentes productos: bolsones con cortes más baratos con un precio accesible, y vender los cortes de carne especiales aparte y con otro precio.

La otra experiencia a analizar es el grupo de horticultores. Este tuvo sus primeros pasos en el año 2014 a partir del programa Municipio Sustentable, a instancias de dicho programa fueron contactados 5 horticultores de la localidad a los fines de que abastezcan parte de la demanda local de verduras frescas. En articulación a esto se sumaron otros productores y se conformó el grupo de productores hortícolas de Cambio Rural II; este grupo ha pasado por varios momentos de activación y caída en la participación, tanto por diferencias entre los productores, con la municipalidad y por fallecimiento de algunos de ellos.

Según un diagnóstico de un funcionario municipal «tienen varios problemas, no tienen tierras, se les vencen los contratos, hay internas en el grupo y con la municipalidad, no tienen tiempo para vender ni vehículos» (Registro de campo, 02/03/2016). En otra ocasión la agente de proyecto de INTA dijo que «la mayoría tiene más superficie de lo que pueden producir. Necesitan herramientas y mano de obra» (Registro de campo, 06/10/2016). A causa de las dificultades para sostener la continuidad de los participantes del grupo, y como es requisito de Cambio Rural ser como mínimo 8 productores, desde el INTA se impulsó la inclusión de más gente «hay 6 quinteros y 6 emprendedores nuevos con idea de arrancar la actividad» (Registro de campo, 06/10/2016). Al igual que con el grupo de cerdos, nuevamente aparece una distinción casi de «calidad» de productores: algunos son «quinteros», otros 
son «emprendedores». De todos modos, la preocupación por la continuidad del grupo fue manifestada en reiteradas reuniones tanto por los representantes de INTA como por los de la municipalidad.

Se ha mencionado que este grupo de Cambio Rural II ha tenido dificultades en su funcionamiento. Para explicar eso los involucrados aludieron a diferentes objetivos, a internas y carencias materiales y formas de concebir la producción. Uno de los productores involucrados en el grupo sostiene que hay inviabilidad en los planteos que hacen desde la coordinación del programa

Y vos los escuchas hablar con los planteos que ellos traían y no era viable porque, te la hago sencilla a la ecuación. Vos tenés un grupo, tenés gente que está produciendo, gente que está empezando y gente que está creciendo, entonces todos necesitan una ayuda, y a todos no nos pueden medir con la misma vara. Al que está empezando no le podes ir a ofrecer una tecnología de punta si no tiene lo básico, que es una sembradora manual, o un equipo de riego, o algo con que mover la tierra. Entonces a esa persona para qué le voy a ir a hablar o le voy a ir a ofrecer un tejido de media sombra y la estructura de un tejido de media sombra si no tiene con qué sembrar abajo de la estructura. (Entrevista S., productor hortícola, 9/3/2017)

Se puede pensar que aquella caracterización homogénea que se hace sobre quiénes son los productores destinatarios de la política tiene sus implicancias a la hora de llevarla a cabo. Es en la experiencia concreta donde se manifiestan las diferencias y a partir de la cual los sujetos «destinatarios» la ponen bajo análisis, la confrontan.

Tanto en el PEA como en Cambio Rural II se hace alusión, aunque marginalmente, a objetivos y metas relacionadas a cuestiones ambientales. Ante las dificultades en el grupo de horticultores y la necesidad de buscar gente nueva que se quiera sumar, el INTA se acercó a un productor de la zona que trabaja en agroecología para invitarlo a formar parte. En una entrevista el hombre contaba:

Vinieron acá al campo, estuvimos charlando con ellos. El Cambio Rural están como queriendo trabajar con el tema de la agroecología, y bueno se dio que yo estoy con esto, charlamos en casa. Es como te digo, yo trato de seguir todo, todo lo que tenga que ver con la agroecología yo dispongo mí tiempo, hago un lugarcito para que esto se siga. Pero allá nos juntamos, toda gente diferente y allá están trabajando con químicos. Hubo un par de reuniones ahí. No puedo 
estar en un grupo que si uno va pa acá y otro va pa allá, así no vamos a llegar nunca a armar un grupo. Es como yo le decía a esta chica ${ }^{12}$, si no vamos por algo común todos, no vamos a llegar nunca a nada. (Entrevista a G., productor hortícola, 9/3/2017)

En este fragmento el horticultor hace referencia a las dificultades de constituir un grupo y sostenerlo a causa de los objetivos e intereses diferentes de los participantes, pero además lleva a pensar que las dificultades no sólo se pueden deber a las individualidades sino a los objetivos de las políticas: por un lado se sostiene la necesidad de aumento de la producción, de la productividad y por otro se plantea la necesidad de la sustentabilidad ambiental y el impulso a la rotación de cultivos y las buenas prácticas agrícolas (que igualmente no es equiparable a agroecología), cuando muchas veces los planteos más productivistas van en detrimento de otros que promueven prácticas agroecológicas. De ahí que los sujetos que participan de los programas, los visualizan como contradictorios o con lógicas contradictorias, tal como lo expresa un productor agroecológico:

Hoy que se yo, el tema del INTA se habla mucho, con el tema de la agroecología, pero mucho hablamos pero no avanzamos nada. Hay proyectos, pero pasan, pasan, pasan y no. No llegan. Es como te digo, como yo le digo a la asesora, el INTA hablamos de agroecología, un grupo del INTA va por acá y el otro va en contra. No se puede así, viste. (Entrevista a G., productor hortícola, 9/3/2017).

Las dificultades en el funcionamiento del grupo generan entre los sujetos productores miembros cierto descreimiento hacia estos proyectos, y se hacen lecturas relacionadas a la burocracia que prima en las relaciones con el Estado:

Y el problema que yo veo que existe es, por ejemplo, yo estoy en una institución y no voy a hablar mal de vos por más que vea que estás haciendo mal las cosas porque en el futuro yo te voy a necesitar a vos, ¿me entendés?[...]. Porque están viendo qué paso dar el día de mañana, y bueno, lamentablemente termina todo en esto. Porque para mí, ellos tienen que llenar planillas, y llenando planillas ellos pasan el 2017; y en el 2018 habrá otras planillas que llenar, y vamos

12. La asesora del grupo de horticultores. 
pasando, y vamos pasando. Pero voluntad de que se den las cosas no hay. (Entrevista S., productor hortícola, 9/3/2017)

Se observa que entre los productores las dificultades en el funcionamiento del grupo se asocian a los diferentes intereses de los involucrados, y a la burocracia o falta de claridad en las propuestas por parte del Estado como impulsor de las políticas públicas. Pero desde la perspectiva de la asesora la clave de los problemas de funcionamiento del grupo radicaba en que los productores buscaban el beneficio personal, poder conseguir algo material. Estas tensiones no pueden dejar de pensarse en términos de las tendencias individualizantes que conviven con propuestas de construcción de un colectivo, y las condiciones materiales de existencia de estos productores y de posibilidades de reproducción de su actividad económica.

A partir de lo descripto hasta el momento parecería que las políticas públicas fuesen un gran bloque de propuestas y pre-nociones alejadas de las necesidades de los sujetos. Sin embargo, además de críticas y cuestionamientos hacia las mismas se puede observar que existe apropiación, ya sea por tomar algunos de sus objetivos, por recuperar su lenguaje: «tengo lechuga amarga, rúcula y lo proceso, que le doy un valor agregado porque al ser poca la cantidad que cosecho le doy más valor de esa forma» (entrevista S., productor hortícola, 9/3/2017). Incluso los productores rescatan en ocasiones la importancia de formar parte de estos espacios ya que a partir de la existencia de las políticas públicas pudieron acceder a beneficios, como ser el financiamiento para equipamiento y las reducciones impositivas por parte de la municipalidad.

También los sujetos hacen sugerencias, más allá de que sean tomadas en cuenta o no. El grupo de horticultores con parte del dinero adquirieron un plantinero para producir los plantines que luego pasarían a tierra, esta estructura estaba instalada en el predio de uno de ellos y aunque era de uso comunitario traía algunos malestares en el grupo. A pesar de ello, el siguiente objetivo del grupo era pedir un tractor con una transplantadora a partir de la evaluación que ellos hacían de falta de mano obra disponible para este tipo de tareas. A partir de la necesidad de maquinaria, y evaluando la falta de mano de obra, 
la precariedad en la ocupación de la tierra y las distancias entre los predios de los productores uno de ellos nos comentaba la propuesta que había hecho:

Pero que pasa, si nos daban un tractor, yo estoy acá, el otro quintero en la otra punta de la ciudad, el otro en la otra punta de la ciudad, el tractor iba a dar 200 mil vueltas y se iba a terminar rompiendo. Y había una cuestión, que todos los productores teníamos un problema, que somos todos inquilinos [...] entonces yo les proponía lo siguiente, que arrendemos 10, 15 ha, nos instalemos ahí adentro con el apoyo municipal. No económico, que vaya una máquina para acomodar el terreno, que con el apoyo municipal se pueda bajar la luz, usar las herramientas esas, tanto el municipio como el INTA para hacer análisis de suelo. Entonces estaríamos agrupados ahí adentro y compartíamos las herramientas porque está en un solo predio, cada uno con sus 2 o 3 ha, y que a la vez el empleado que nosotros podríamos traer. (Entrevista S., productor hortícola, 9/3/2017)

A pesar de que a primera vista pareciera interesante la propuesta y que solucionaría algunas de las dificultades (tanto individuales como colectivas), el productor comenta que en el grupo había divisiones, que a algunos les había gustado la propuesta pero que la «dirigencia» de INTA se oponía y decía que debían conseguir una sala de extracción. Finalmente la propuesta no fue considerada, pese a ello es interesante recuperar este relato no sólo por el lugar activo del sujeto sino también porque da cuenta de que la política pública toma cuerpo cuando se generan instancias de intercambio y discusión entre técnicos, productores y gobierno local, y cuando hay una búsqueda de articulación entre diferentes programas (Cambio Rural II y Municipio Sustentable).

Shore (2009) plantea que las políticas son herramientas de intervención, que tienen un carácter instrumental pero también simbólico. Y considerando la recuperación de la experiencia cotidiana de los sujetos en el desarrollo y generación de las políticas públicas es factible decir que las características instrumentales y simbólicas no son únicamente las planteadas desde los formuladores de políticas públicas. Si entendemos que las políticas sobrepasan lo gubernamental, e incluyen la participación de otros sujetos, o sea, se constituyen en la cotidianeidad, pueden pensarse como un espacio de disputa de hegemonía. 


\section{Consideraciones finales}

Analizar las políticas públicas desde una perspectiva socio-antropológica es una tarea de grandes dimensiones que no se agotan en este trabajo. Sin embargo considero que he podido iniciar un proceso que puede ayudar a comprender de una forma relacional lo que sucede en una localidad respecto a identidades, prácticas productivas, sentidos sobre las políticas públicas puestas en juego entre las lógicas de gobierno y la de los sujetos.

A su vez, el análisis de las políticas públicas constituyó una perspectiva que suma a comprender los procesos generales e históricos que se vienen desarrollando en el agro argentino. La profundización de las relaciones capitalistas en el agro con las consecuentes transformaciones en la forma de llevar a cabo la producción y en los estilos de vida y consumo de la población, en este caso particular de localidades vinculadas a la producción agropecuaria, tiene profundas conexiones con los planes, políticas y programas impulsados desde diferentes niveles de Estado. En la localidad bajo estudio, las imbricaciones de lo urbano y lo rural forman parte de la cotidianidad social de quienes allí habitan y es histórica; y con ello me refiero no sólo a que existen desde largo tiempo sino que también han ido sufriendo transformaciones. Quizás hoy, las tendencias a la concentración de la producción, la especialización en la agricultura y en un cultivo, la intensificación del capital se constituye en marco de algunos procesos conflictivos en las localidades. A su vez, son el contexto en que se construyen una serie de políticas públicas que se proponen modificar esa situación, pero que sin embargo no están libres de contradicciones al inscribirse y propiciar esas mismas tendencias generales que buscan transformar.

Un aspecto que quisiera destacar es que a pesar de que en la letra y desde el poder las políticas se presentan como un asunto de técnicos-expertos, y parecen ser un diagnóstico certero de situación con su correspondiente instructivo de intervención, en el «terreno», cuando pasan de la letra a la experiencia su naturaleza política se manifiesta a través de las contradicciones, cuestionamientos, apropiaciones y reformulaciones que hacen los sujetos involucrados en ellas. De ahí que las políticas públicas sean comprendidas como espacios de relación que incluyen los procesos y actuaciones desplegados tanto por organizaciones e instituciones estatales y como por los diferentes sujetos implicados. 
A partir del análisis del programa Cambio Rural II y su vinculación con una política mayor como es el PEA fue posible dar cuenta de construcciones sobre el sujeto social agrario que tienden a querer desdibujar la heterogeneidad bajo la figura del «emprendedor», la cual al individualizar genera dificultades para la construcción colectiva o es un punto de tensión en los grupos de productores (tanto de porcinos como horticultores). Podemos inferir que esto se vincula a la construcción de un modelo societal rural y subjetividades específicas asociadas a los sectores más concentrados de la economía agropecuaria nacional, a los fines de seguir profundizando las relaciones capitalistas en el campo. En su relación y articulación con el programa local Municipio Sustentable es posible inferir que las particularidades de la localidad, la centralidad del espacio del periurbano como foco de interés posibilitó un encuentro y problematización sobre qué se produce en la localidad, para quienes se producen, así como vislumbrar la centralidad de pequeños y medianos productores de alimentos si se pretende reflexionar sobre los términos de esa relación siempre compleja de lo urbano y lo rural.

Finalmente, quisiera agregar que pese a cierta predominancia de formas de llevar a cabo la producción y de subjetividades neoliberales, como la hegemonía no es absoluta sino un proceso disputado, otras subjetividades y otras formas de llevar a cabo o pensar la producción agropecuaria siguen persistiendo, apropiándose y reformulando las políticas públicas. Esto plantea el desafío de pensar en continuidades y rupturas o en lo residual y lo emergente (Williams, 2009) en las políticas públicas.

\section{Referencias}

ACHILLI, E. (1998). «Vivir en la pobreza urbana. El derecho a una interculturalidad no excluyente». Revista Lote, (18).

ACHILli, E. (2005) Investigar en Antropología Social. Los desafios de transmitir un oficio. Rosario, Argentina: Laborde Editor.

ACHILli, E. (2014). «Hacer antropología. Los desafíos del análisis a distintas escalas». III Seminario Taller de la RED DE INVESTIGADORES EN ANTROPOLOGÍA Y EDUCACIÓN (RIAE) «Politicas y transformaciones educativas: perspectivas etnográficas en América Latina». Facultad de Filosofía y Letras-UBA. 
Acosta, A. (2011). Extractivismo y neoextractivismo: dos caras de la misma maldición. Disponible en https://alineadefuego.info/2011/12/23/ extractivismo-y-neoextractivismo-dos-caras-de-la-misma-maldicion-por-alberto-acosta/

BARSKy, A. (2005). El periurbano productivo, un espacio en constante transformación.

Introducción al estado del debate, con referencias al caso de Buenos Aires. Scripta Nova Revista electrónica de Geografía y Ciencias Sociales, (194) (36).

Borón, A. (2001). El nuevo orden imperial y como desmontarlo. En J. Seoane y E. Taddei (comps.), Resistencias mundiales (De Seattle a Porto Alegre) (pp. 31-62). Buenos Aires: Clacso.

Cloquell, S (coord.); Albanesi, R; Nogueira, M; Propersi, P. (2014). Pueblos Rurales. Territorio, sociedad y ambiente en la nueva agricultura. Ediciones Ciccus. Buenos Aires

Cosecha récord para la Argentina: 136 millones de toneladas. (26 de septiembre de 2017). Infobae. Recuperado de https://www.infobae.com/ economia/2017/09/26/cosecha-record-para-la-argentina-136-millones-de-toneladas/

Delgado, P. (2018). Espíritu emprendedor: notas sobre emprendedorismo, neoliberalismo y subjetividad. Recuperado de http://contrahegemoniaweb.com.ar/espiritu-emprendedor-notas-sobre-emprendedorismo-neoliberalismo-y-subjetividad/

Galbraith, J. (1992). La cultura de la satisfacción. Buenos Aires: Emecé editores.

Giarraca, N. (2003). Territorios y lugares. Entre las fincas y la ciudad. Lules en Tucumán. Buenos Aires: La Colmena.

Gonzalez Carballo, C.; Boucau, F. Y Moreira, C.(2012). Plan estratégico Agroalimentario y Agroindustrial 2010-2020. Desafíos crecientes para un desarrollo rural sustentable.EnXVI Jornadas Nacional de Extensión Rural y VIII del Mercosur.

Heller, A. (1977). Sociología de la vida cotidiana. Barcelona: Península.

inta- Ministerio de Agricultura, Ganadería y Pesca de la Nación. (s/f). Cambio Rural II. Innovación e inversión (manual operativo). 
inta- Ministerio de Agricultura, Ganadería y Pesca de la Nación. (2014). Innovación e inversión. Cambio Rural II. INTA Informa, Año XIII - (145).

Ministerio de Agricultura, Ganadería y Pesca de la Nación. (2010). Plan Estratégico Agroalimentario y Agroindustrial Participativo y Federal 2010-2020.

PAgINA DE LA SECRETARÍA DE AGROINDUSTRIA DE LA NACION. http://datosestimaciones.magyp.gob.ar

Perez, M., González, E., Pérez, R., De luca, L., Tito, G., Propersi, P. y Albanesi, R. (2013). Protocolo recomendatorio. Desarrollo de producciones agroecológicas en zonas periurbanas de localidades pampeanas con restricciones para las pulverizaciones con agroquímicos. Buenos Aires: Ediciones INTA.

Programa Municipio Sustentable (2014)

RockWell, E. (2011). La experiencia etnográfica. Historia y cultura en los procesos educativos. Buenos Aires: Paidós.

Reboratti, C. (2017). Agricultura y extractivismo. Voces en el Fénix (60), 118-125.

Shore, C. (2010). La antropología y el estudio de la política pública: reflexiones sobre la «formulación» de las políticas. Antípoda (10), 21- 49 .

Solá, F. (12 de agosto de 1995). Una reforma cultural. Clarín Rural, p.5

Svampa, M. Y Viale, E. (2017). Continuidad y radicalización del neoextractivismo en la Argentina. Voces en el Fénix (60), 26-35.

Williams, R. (2009). Marxismo y literatura. Buenos Aires: Las Cuarenta. 